\title{
CHEMICAL CHARACTERIZATION OF CARDIAC MYOSIN FROM NORMAL DOGS AND FROM DOGS WITH CHRONIC CONGESTIVE HEART FAILURE
}

\author{
BY JAMES O. DAVIS, WILLIAM R. CARROLL, MARY TRAPASSO AND \\ NICHOLAS A. YANKOPOULOS WITH THE SURGICAL ASSISTANCE OF \\ ALFRED CASPER
}

\author{
(From the Section on Experimental Cardiovascular Disease, Laboratory of Kidney and \\ Electrolyte Metabolism, National Heart Institute, and the Section on Physical \\ Biochemistry, Laboratory of Physical Biology, National Institute of \\ Arthritis and Metabolic Diseases, Bethesda, Md.)
}

(Submitted for publication January 18, 1960; accepted March 31, 1960)

The size and chemical nature of the myosin molecule have been studied extensively in enzyme preparations obtained from skeletal muscle (1-7), but a paucity of data is available on cardiac myosin. Furthermore, different values for the molecular weight of cardiac myosin have been reported. Olson (8) reported a value of 223,000 for the molecular weight of cardiac myosin whereas Gergely and Kohler (9) presented evidence that myosin from cardiac muscle has a molecular weight of 500,000 , which is similar to that obtained during the most recent observations on skeletal muscle myosin (4-7).

It has been suggested that the cardiac myosin molecule is altered in cardiac failure to form a stable aggregate of the basic monomer and that abnormal myosin prevents the formation of normal cardiac actomyosin (8). On the contrary, considerable evidence has been adduced that actomyosin from the failing heart is normal (10). The present observations were undertaken to determine the molecular size and chemical nature of normal cardiac myosin and to compare these data with results obtained on cardiac myosin from dogs with chronic congestive heart failure.

\section{METHODS}

Muscle was obtained from the hearts of 12 normal dogs, 11 dogs with right-sided cardiac failure secondary to surgically-induced tricuspid insufficiency and pulmonic stenosis, one dog with naturally occurring right- and left-sided congestive failure and 3 dogs with chronic ascites produced by constriction of the thoracic inferior vena cava. The techniques used for the surgical procedures have been described previously (11-13). On the day of sacrifice, studies were conducted to determine the physiological state of the animals. All measurements of cardiovascular pressures were made in trained unanesthetized dogs; the methods have been described previously (13). The methods for $\mathrm{Na}$ balance measurements are described elsewhere $(11,12) ; \mathrm{Na}$ intake was $60 \mathrm{mEq}$ per day.

Cardiac muscle was obtained by anesthetizing the animals lightly with intravenous sodium pentobarbital, opening the chest quickly and excising the beating heart. The heart was washed with cold water and placed in a container with chipped ice. The right and left ventricular walls were separated from the septum. Since only rightsided heart failure was present in dogs with tricuspid insufficiency and pulmonic stenosis (13), muscle from the right and from the left ventricles of these dogs was extracted separately for myosin. The left ventricle only was used for preparation of myosin from the one dog with naturally occurring right- and left-sided cardiac failure and from the dogs with constriction of the thoracic inferior vena cava. Myosin was extracted from combined right and left ventricles of normal dogs.

Myosin was prepared by the method of Gergely (14). The extraction of myosin was begun immediately after obtaining heart muscle. Since the yield of myosin was low, all of the right or left ventricular muscle masses was used. To obtain enough myosin for diffusion measurements, in some instances the right ventricles from 2 dogs were combined for extraction and the left ventricles from the same animals were extracted as one preparation. The procedure to be described for the extraction of myosin applies for a quantity of $75 \mathrm{~g}$ of cardiac muscle. If less muscle was available, the volumes of the extracting media were adjusted accordingly. The entire extraction procedure was carried out at $0^{\circ}$ to $5^{\circ} \mathrm{C}$.

Seventy-five $g$ of heart muscle was ground with a meat grinder and extracted with $300 \mathrm{ml}$ of a salt solution by stirring for 45 minutes. The salt solution contained 0.3 $\mathrm{M} \mathrm{KCl}, 0.2 \mathrm{M}$ potassium phosphate buffer ( $\mathrm{pH} 6)$ and $0.02 \mathrm{M}$ sodium pyrophosphate; the final $\mathrm{pH}$ of the solution was adjusted to 6.2 with $\mathrm{KOH}$. The muscle extract was squeezed through cheesecloth and the residue discarded. The extract was centrifuged at $2,000 \mathrm{rpm}$ in a Lourdes model AT centrifuge for 30 minutes. To precipitate the myosin, 10 volumes of glass distilled water were added to each volume of the supernatant. The precipitate of myosin was allowed to settle for at least 1 hour and the supernatant was siphoned off. The remaining myosin solution was centrifuged at $8,000 \mathrm{rpm}$ in the Lourdes centrifuge for 10 minutes. The supernatant was discarded and the residue was dissolved in $2.4 \mathrm{M}$ 
TABLE I

Physiological data on experimental animals at the time of sacrifice

\begin{tabular}{|c|c|c|c|c|c|c|c|c|c|c|c|}
\hline \multirow[t]{2}{*}{$\begin{array}{l}\text { Dog } \\
\text { no. }\end{array}$} & \multirow{2}{*}{$\begin{array}{c}\begin{array}{c}\text { Initial } \\
\text { body } \\
\text { wt }\end{array} \\
k g\end{array}$} & \multirow{2}{*}{$\begin{array}{c}\begin{array}{c}\text { Time } \\
\text { after } \\
\text { last } \\
\text { operation }\end{array} \\
\text { days }\end{array}$} & \multirow{2}{*}{$\begin{array}{c}\begin{array}{c}\text { Duration } \\
\text { of } \\
\text { ascites }\end{array} \\
\text { days }\end{array}$} & \multirow{2}{*}{$\begin{array}{c}\begin{array}{c}\text { Volume } \\
\text { of } \\
\text { ascites }\end{array} \\
L\end{array}$} & \multirow{2}{*}{$\begin{array}{c}\begin{array}{c}\text { Renal } \\
\mathrm{Na} \\
\text { excretion }\end{array} \\
m E q / d a y\end{array}$} & \multirow{2}{*}{$\frac{\underset{\mathrm{Na}}{\text { Plasma }}}{m E q / L}$} & \multirow{2}{*}{$\frac{\underset{\mathrm{K}}{\text { Plasma }}}{m E q / L}$} & \multicolumn{2}{|c|}{$\begin{array}{c}\text { Mean right } \\
\text { atrial } \\
\text { pressure } \\
\text { Ct }\end{array}$} & \multicolumn{2}{|c|}{$\mathrm{C}^{\text {LVEDP* }} \mathrm{E}$} \\
\hline & & & & & & & & \multicolumn{2}{|c|}{$m m$ water } & \multicolumn{2}{|c|}{$m m$ water } \\
\hline \multicolumn{12}{|c|}{ Dogs with right-sided failure produced by tricuspid insufficiency and pulmonic stenosis } \\
\hline $\begin{array}{r}1 \\
2 \\
3 \\
4 \\
5 \\
6 \\
7 \\
8 \\
9 \\
10 \\
11\end{array}$ & $\begin{array}{l}18.3 \\
21.5 \\
20.5 \\
17.0 \\
19.0 \\
18.9 \\
18.5 \\
25.0 \\
20.5 \\
19.0 \\
18.6\end{array}$ & $\begin{array}{r}91 \\
118 \\
195 \\
144 \\
55 \\
86 \\
86 \\
69 \\
88 \\
74 \\
75\end{array}$ & $\begin{array}{r}80 \\
88 \\
192 \\
132 \\
51 \\
79 \\
68 \\
68 \\
85 \\
68 \\
71\end{array}$ & $\begin{array}{l}8.00 \\
0.20 \\
4.90 \\
1.65 \\
2.80 \\
0.61 \\
3.00 \\
3.50 \\
3.70 \\
0.01 \\
0.10\end{array}$ & \begin{tabular}{r|}
5.9 \\
2.5 \\
1.4 \\
32.6 \\
50.5
\end{tabular} & $\begin{array}{l}151 \\
155 \\
142 \\
144 \\
141 \\
137 \\
149 \\
152 \\
147 \\
148\end{array}$ & $\begin{array}{l}3.9 \\
4.3 \\
4.3 \\
4.7 \\
3.9 \\
4.3 \\
4.7 \\
3.5 \\
3.8\end{array}$ & $\begin{array}{l}76 \\
65 \\
98 \\
60 \\
40\end{array}$ & $\begin{array}{l}240 \\
175 \\
190 \\
330 \\
140 \\
144 \\
152 \\
275 \\
205 \\
165 \\
180\end{array}$ & $\begin{array}{r}95 \\
81 \\
\\
119 \\
75 \\
108\end{array}$ & $\begin{array}{r}99 \\
55 \\
65 \\
108\end{array}$ \\
\hline$\overline{\mathrm{x}}$ & 19.8 & 98.2 & 89.2 & 2.59 & 19.0 & 147 & 4.2 & 65 & 199 & 96 & 66 \\
\hline \multicolumn{12}{|c|}{ Dog with naturally occurring right- and left-sided heart failure } \\
\hline 1 & 41.0 & & 150 & 1.20 & & 153 & 3.6 & & 230 & & 210 \\
\hline \multicolumn{12}{|c|}{ Dogs with constriction of the thoracic inferior vena cava } \\
\hline $\begin{array}{l}1 \\
2 \\
3\end{array}$ & $\begin{array}{l}17.9 \\
18.0 \\
22.0\end{array}$ & $\begin{array}{r}92 \\
74 \\
166\end{array}$ & $\begin{array}{r}88 \\
61 \\
165\end{array}$ & $\begin{array}{r}3.00 \\
4.50 \\
\cdot \quad 2.50\end{array}$ & $\begin{array}{l}1.9 \\
7.5 \\
0.6\end{array}$ & $\begin{array}{l}143 \\
144 \\
140\end{array}$ & $\begin{array}{l}4.1 \\
3.8 \\
4.7\end{array}$ & & $\begin{array}{l}280 \ddagger \\
175 \ddagger \\
165 \ddagger\end{array}$ & & $\begin{array}{l}75 \\
75 \\
63\end{array}$ \\
\hline
\end{tabular}

* LVEDP is the abbreviation for left ventricular end-diastolic pressure.

$\dagger \mathrm{C}$ and $\mathrm{E}$ are abbreviations for control and experimental, respectively.
$\ddagger$ Inferior vena caval pressures instead of right atrial pressures.

$\mathrm{KCl}$. The solution of myosin was diluted to $0.6 \mathrm{M} \mathrm{KCl}$ and enough $0.6 \mathrm{M} \mathrm{KCl}$ was added to make $100 \mathrm{cc}$. Potassium carbonate was added to adjust the $\mathrm{pH}$ to 7.5 and the solution was stirred overnight with a magnetic stirrer. The preparation was centrifuged at $16,500 \mathrm{rpm}$ for 30 minutes, in the Lourdes centrifuge. The myosin was precipitated for the second time by adding again 10 volumes of glass distilled water to each volume of myosin solution. The myosin was allowed to settle and the supernatant was siphoned off and discarded. The myosin solution was centrifuged at $8,000 \mathrm{rpm}$ for 10 minutes. The residue was dissolved in $2.4 \mathrm{M} \mathrm{KCl}$, diluted to $0.6 \mathrm{M}$ $\mathrm{KCl}$ and sufficient $0.6 \mathrm{M} \mathrm{KCl}$ was added to make $100 \mathrm{cc}$. The $\mathrm{pH}$ was adjusted to 7 with potassium carbonate. The solution was diluted to $0.3 \mathrm{M}$ and centrifuged at $8,000 \mathrm{rpm}$ for 10 minutes in the Lourdes centrifuge. The third precipitation was carried out by further dilution to a $0.06 \mathrm{M}$ solution. The myosin solution was allowed to settle overnight. The supernatant was siphoned off and the remainder was centrifuged at $8,000 \mathrm{rpm}$ for $10 \mathrm{~min}$ utes. The residue was dissolved in $2.4 \mathrm{M} \mathrm{KCl}$ and the concentration was adjusted to $0.6 \mathrm{M} \mathrm{KCl}$. The myosin preparation was centrifuged at $16,500 \mathrm{rpm}$ for 30 minutes in the Lourdes centrifuge. The supernatant myosin solution was decanted from the pellet and centrifuged in a Spinco model $\mathrm{L}$ ultracentrifuge for 4 hours at $30,000 \mathrm{rpm}$. The final myosin solution was decanted from the pellet. The yields ranged from 75 to $200 \mathrm{mg}$ per $100 \mathrm{~g}$ of cardiac muscle. ${ }^{1}$

1 No attempt was made to compare the yields of myosin from normal and failing cardiac muscle. The aim of the extraction procedure was to achieve purity of preparation and the large losses of myosin which occurred would make any attempt at quantitation meaningless.
Measurements of sedimentation velocity of cardiac myosin were made with a Spinco model $E$ analytical ultracentrifuge. Two samples were centrifuged simultaneously by use of a wedge cell and a plain cell. Either two different concentrations of myosin or one concentration of myosin with added ATP and $\mathrm{MgCl}_{2}$ and the same preparation and concentration of myosin without these compounds were centrifuged. The final concentrations of ATP and $\mathrm{MgCl}_{2}$ were $5 \times 10^{-3} \mathrm{M}$ and $10^{-3} \mathrm{M}$, respectively. Kel $\mathrm{F}$ centerpieces were used to prevent denaturation of the protein. Ultracentrifugation ${ }^{2}$ was performed at $59,780 \mathrm{rpm}$ or $250,000 \mathrm{G}$ at a temperature of $7^{\circ} \mathrm{C}$; the bar angle was $60^{\circ}$. Actual sedimentation constants were corrected to $20^{\circ} \mathrm{C}$ and to water as a solvent by the standard formula (15). A value of 0.728 was used for the partial specific volume of myosin.

Diffusion measurements were made in an Aminco model $\mathrm{B}$ electrophoresis apparatus at $6^{\circ} \mathrm{C}$, using carefully selected cells and the Raleigh interferometer in the manner described by Longsworth (16). The myosin solutions were dialyzed for 18 to 20 hours against $0.6 \mathrm{M} \mathrm{KCl}$ buffered to $\mathrm{pH} 7.6$ with phosphate. Diffusion coefficients were corrected to $20^{\circ} \mathrm{C}$ and to water as a solvent. Sedimentation constants were determined on all but one of the myosin preparations used for diffusion measurements.

Viscosity was measured with a size II Ubbelohde viscosimeter with an outflow time for $0.6 \mathrm{M} \mathrm{KCl}$ of 100 seconds. All viscosity measurements on myosin were made within the first day or two after completion of the

2 Slight variation in the $S_{20, w}$ has been reported with different rotor speeds (3). Ultracentrifugation was performed at $59,780 \mathrm{rpm}$ because measurements are more accurate with this rotor speed than with slower rates of sedimentation for large molecules such as myosin $(3,15)$. 
preparation. Myosin was dissolved in $0.6 \mathrm{M} \mathrm{KCl}$ and measurements were made in a constant temperature water bath at $22.5^{\circ} \pm 0.02^{\circ} \mathrm{C}$. Multiple determinations on a myosin preparation were made by repeated dilution of the myosin solution and subsequent measurement of the viscosity. The relative viscosity $\left(\eta_{\mathrm{re} 1}\right)$ was determined as the ratio of the outflow time for the solution of myosin to that of $0.6 \mathrm{M} \mathrm{KCl} ; \eta_{\mathrm{sp}}$ is equal to $\eta_{\mathrm{ret}}{ }^{-1}$.

The protein concentration of the myosin solutions was determined by micro-Kjeldahl analysis.

\section{RESULTS}

Physiological studies of experimental animals. The results are presented in Table I. The 11 dogs with tricuspid insufficiency and pulmonic stenosis showed evidence of pure right-sided congestive failure. Mean right atrial pressure was markedly elevated in every instance, whereas left ventricular end-diastolic pressure was normal. Ascites was present in all dogs but $\mathrm{Na}$ excretion varied from 1.4 to $50.5 \mathrm{mEq}$ per day. The ratio of right ventricular to left ventricular weight was 0.93 in comparison with the normal value of 0.51 (13) $(\mathrm{p}<0.001)$. Other previously reported data (13) on heart and lung weights in dogs with cardiac failure secondary to tricuspid insufficiency and pulmonic stenosis showed no evidence of left ventricular failure or hypertrophy. The average duration of life after the second operation (production of pulmonic stenosis) was 98 days, whereas the average duration of ascites was 89 days.

The one animal with naturally occurring congestive heart failure showed evidence of both right and left ventricular hypertrophy and failure. The filling pressures in both the right and the left heart were elevated. The heart was massively enlarged and weighed $502 \mathrm{~g}$. The lungs weighed almost 2.5 times the average normal value of $9.15 \pm 1.30 \mathrm{~g}$ per $\mathrm{kg}$ (13) and showed microscopic evidence of chronic passive congestion. The liver showed evidence histologically of chronic congestion and presented the characteristic nutmeg appearance grossly.

In addition to the normal animals, three dogs with thoracic caval constriction and chronic ascites provided control material. These animals were not in cardiac failure but they showed essentially the same alterations in salt and water metabolism and the protein depletion observed in experimental heart failure (11-13). Consequently, cardiac muscle from the dogs with caval constriction pro- vided a control for evaluation of possible changes in failing heart muscle which might be secondary to altered electrolyte or protein metabolism. Data on their physiological state are presented in Table I. An additional finding of interest in these animals is the presence of both right and left ventricular atrophy which has been reported elsewhere (13).

Sedimentation velocity studies of myosin. The sedimentation of myosin was observed in enzyme preparations made from the combined right and left ventricles of normal dogs. Myosin from separate right and left ventricles of $\operatorname{dog} \mathrm{s}$ with right heart failure secondary to tricuspid insufficiency and pulmonic stenosis was studied while left ventricular myosin only was obtained from dogs with constriction of the thoracic inferior vena cava. In addition, studies were made on myosin from the left ventricle of a dog with naturally occurring right- and left-sided failure.

Qualitatively the sedimentation patterns were identical for myosin from all sources of cardiac muscle. The typical sedimentation pattern consisted of a single peak which suggested homogeneity of the myosin preparation (Figure 1). In a few instances, a very small boundary which sedimented faster than the principal myosin component was observed. The magnitude of this boundary was not sufficient to produce sedimentation constants which were different from those obtained in myosin preparations with only one sedimentation boundary. Addition of ATP immediately before centrifugation did not influence the sedimentation pattern or rate of movement of myosin (Figure 1).

Quantitative data on sedimentation velocity are presented in Figure 2. The $\mathrm{S}_{20, \mathrm{w}}$ at zero concentration for myosin from normal heart muscle was $6.17 \times 10^{-13}$ seconds. The slopes of the least squares straight lines and the $y$ intercepts (Figure 2) for the myosin from failing right or left ventricles, from the nonfailing left ventricle of dogs with tricuspid insufficiency and pulmonic stenosis, and from the atrophic left ventricle of dogs with thoracic caval constriction were not statistically different from the values for normal cardiac myosin. Both the slope of the line and the $y$ intercept for myosin from the left ventricle of dogs with tricuspid insufficiency and pulmonic stenosis were 

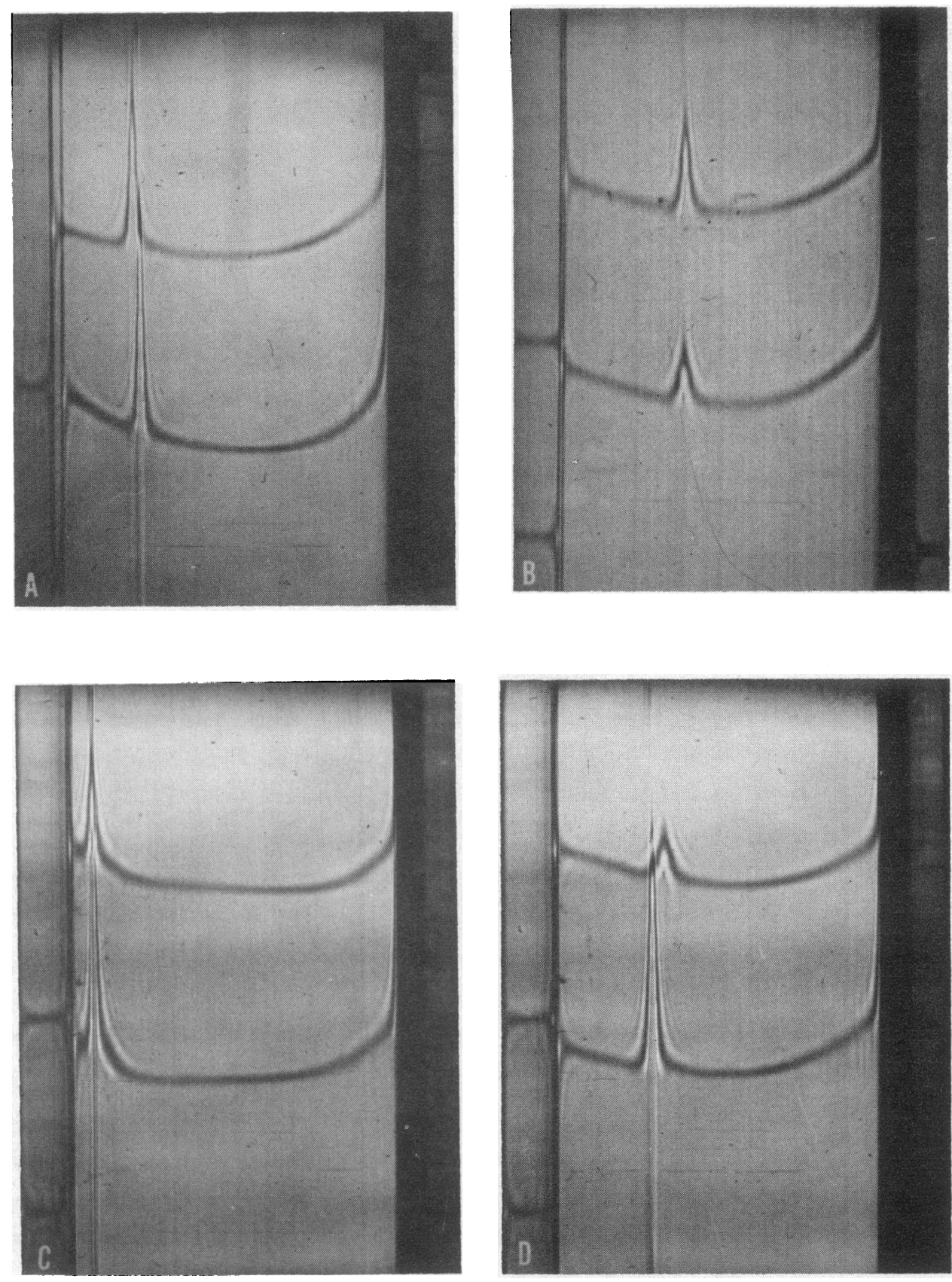

Fig. 1. Ultracentrifugal sedimentation patterns of Cardiac myosin. Centrifugation was carried out at $59,780 \mathrm{rpm}$; bar angle was $60^{\circ}$. In A, cardiac myosin (approximately 3.0 $\mathrm{mg}$ per $\mathrm{ml}$ ) from a normal dog in upper part of picture (wedge cell) and the same preparation with added ATP in the lower picture (regular cell); photograph taken at 52 minutes after reaching maximal speed. In $B$, two concentrations $(1.5$ and $1.0 \mathrm{mg}$ per $\mathrm{ml}$ ) of cardiac myosin from a normal dog after completion of diffusion measurements; picture taken after 72 minutes at a speed of $59,780 \mathrm{rpm}$. In $C$ and $D$, cardiac myosin in concentrations of 0.9 and $2.5 \mathrm{mg}$ per $\mathrm{ml}$ from a dog with experimental congestive heart failure secondary to tricuspid insufficiency and pulmonic stenosis; photograph in $\mathrm{C}$ was taken 12 minutes after reaching maximal speed while picture in $\mathrm{D}$ was taken after 68 minutes. 

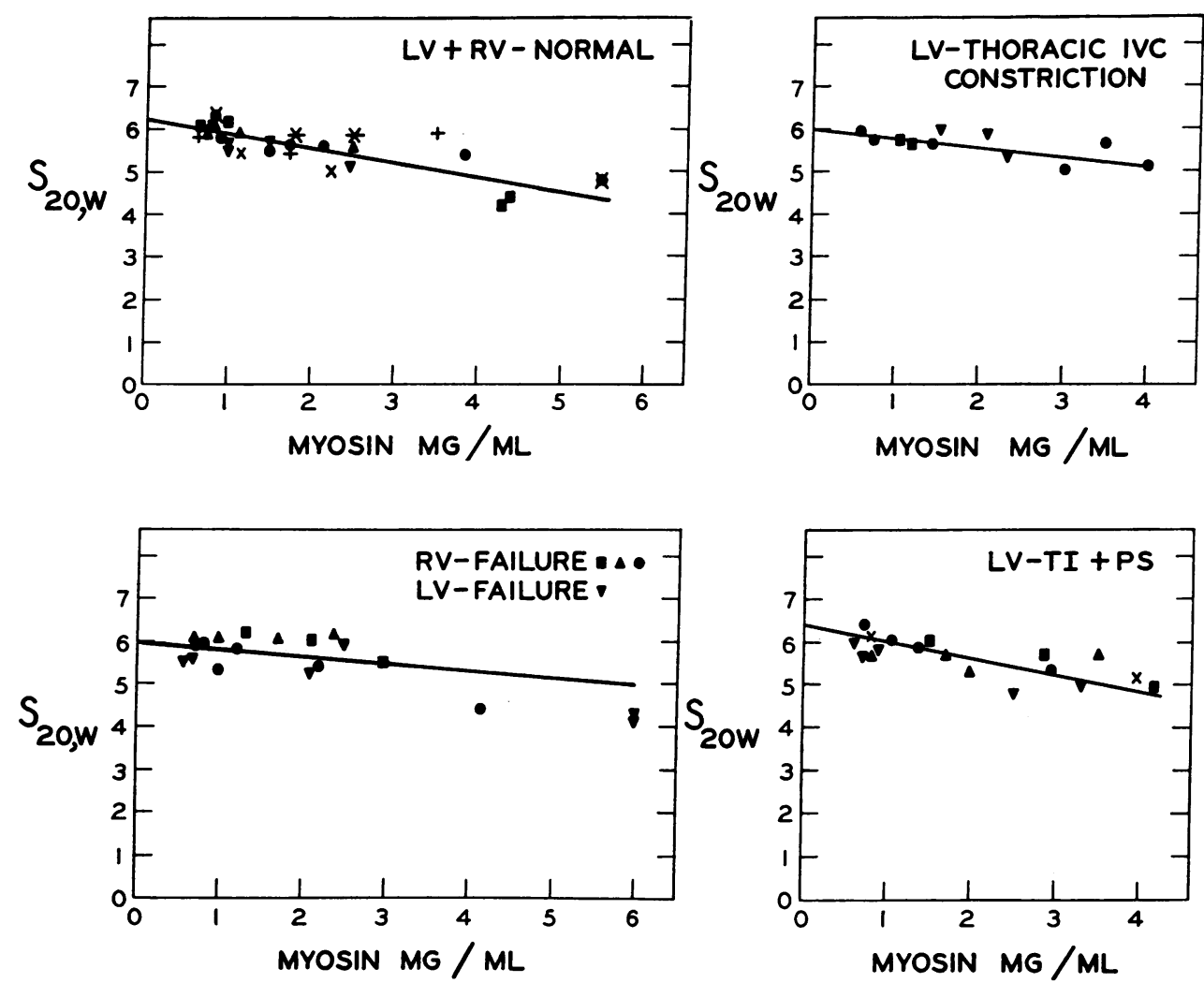

Fig. 2. Sedimentation CONSTANTS $\left(\mathrm{S}_{20, \mathrm{w}}\right)$ FOR MYOSIN FROM FOUR DIFFERENT SOURCES PLOTTED AGAINST THE PROTEIN CONCENTRATION. Each symbol represents myosin from a different preparation. Right ventricular failure was secondary to tricuspid insufficiency and pulmonic stenosis. Left ventricular failure was present in the one dog with naturally occurring cardiac failure. RV and LV are abbreviations for right ventricle and left ventricle, respectively. The weighted least squares straight lines are drawn for each group.

significantly greater $(p<0.01)$ than those for myosin from the failing heart.

Diffusion measurements on myosin. Data on the rates of diffusion of myosin from normal cardiac muscle and from cardiac muscle of dogs with cardiac failure are presented in Figure 3. Extrapolation of the $\mathrm{D}_{\mathbf{2 0 , \mathrm { w }}}$ to zero concentration for normal cardiac myosin yields a value of 1.1 $\times 10^{-7} \mathrm{~cm}^{2}$ per second. No differences are apparent in the rates of diffusion of myosin from the normal and experimental material.

Evidence of heterogeneity of the myosin preparations was obtained from analysis of the normalized fringe distances [see Longsworth (16)] at different levels in the diffusing boundary. Maximum deviation of these distances was about 12 per cent, indicating variations of average diffusion coefficients of at least 25 per cent. This indication of polydispersity was apparent in myosin solutions from both normal and experimental hearts.

$V$ iscosity measurements. The viscosity of myosin was measured in enzyme preparations from the combined right and left ventricular masses of normal dogs, from separate right and left ventricles of dogs with right-sided failure secondary to tricuspid insufficiency and pulmonic stenosis, and from the left ventricle only of dogs with thoracic caval constriction. The results are presented in Figure 4 where $\eta_{\mathrm{sp}} / \mathrm{C}$ is plotted against the concentration of myosin. For normal cardiac myosin, an excellent linear relation between $\eta_{\mathrm{sp}} / \mathrm{C}$ and concentration with evidence of concentration dependence is present between concentrations of 3.5 and $0.4 \mathrm{mg}$ per $\mathrm{ml}$. In the very dilute solutions of myosin (below $0.4 \mathrm{mg}$ per $\mathrm{ml}$ ), the results varied among different enzyme preparations. With 


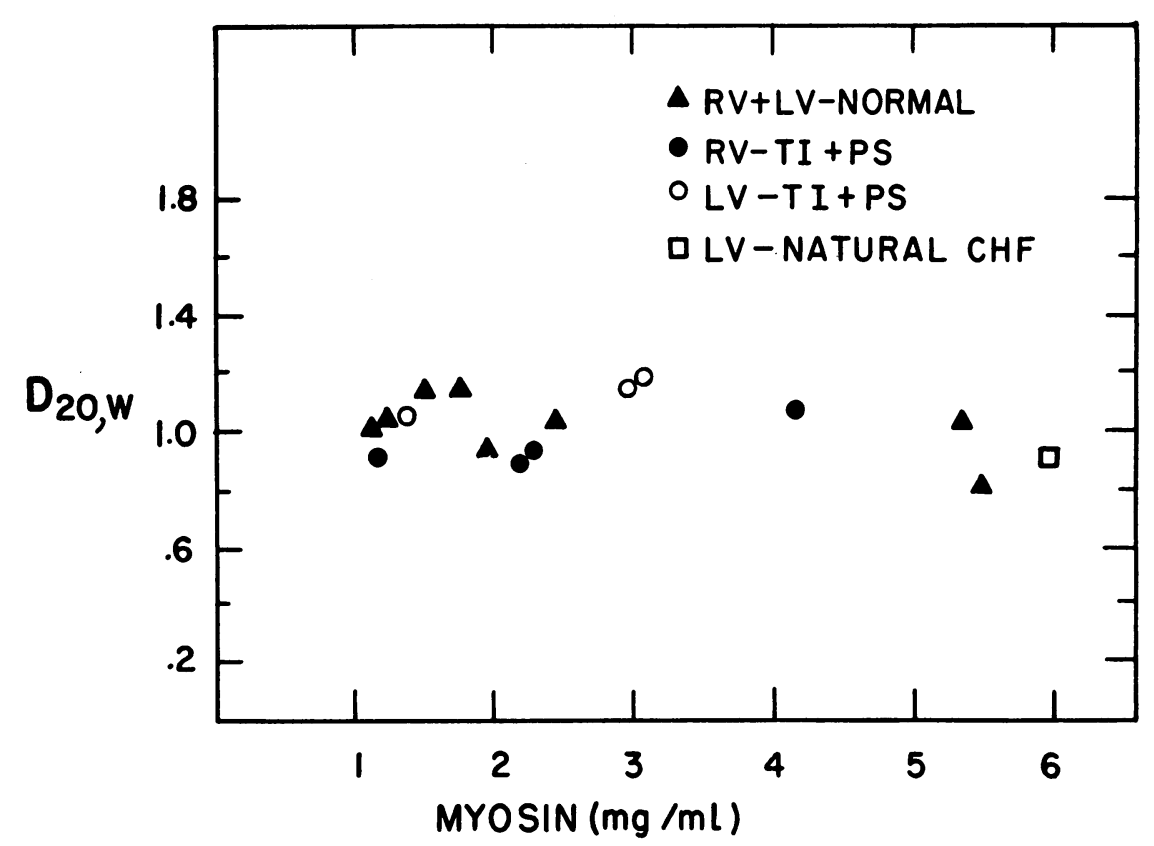

Fig. 3. Diffusion Coefficients ( $\mathrm{D}_{\mathbf{3}, \mathrm{w}}$ ) For myosin plotted against protein CONCEntration. The symbols $\bullet$ and $\square$ are for myosin from failing ventricular muscle, whereas $\boldsymbol{\Delta}$ and $\bigcirc$ represent myosin from normal muscle and from nonfailing left ventricle of dogs with tricuspid insufficiency (TI) and pulmonic stenosis (PS), respectively. $\mathrm{CHF}$ is the abbreviation for congestive heart failure.

one myosin preparation, the $\eta_{\mathrm{sp}} / \mathrm{C}$ fell almost to zero, whereas in two other preparations $\eta_{\mathrm{sp}} / \mathrm{C}$ increased. If this peculiar behavior at low concentrations is neglected, the intrinsic viscosity $\left(\eta_{\mathrm{sp}} / \mathrm{C}\right.$ at zero concentration) is 1.8. Cardiac myosin from dogs with thoracic caval constriction provided another source of control material (Figure $4)$; the peculiar viscosity values at very low concentrations were again observed.
The viscosity of myosin from the right ventricle of dogs with right-sided congestive failure did not appear to differ from myosin from normal dogs or dogs with caval constriction. Both myosin from the right ventricle and myosin from the left ventricle of dogs with right heart failure secondary to tricuspid insufficiency and pulmonic stenosis showed an increase in viscosity at low concentrations. Also, one myosin preparation from the left

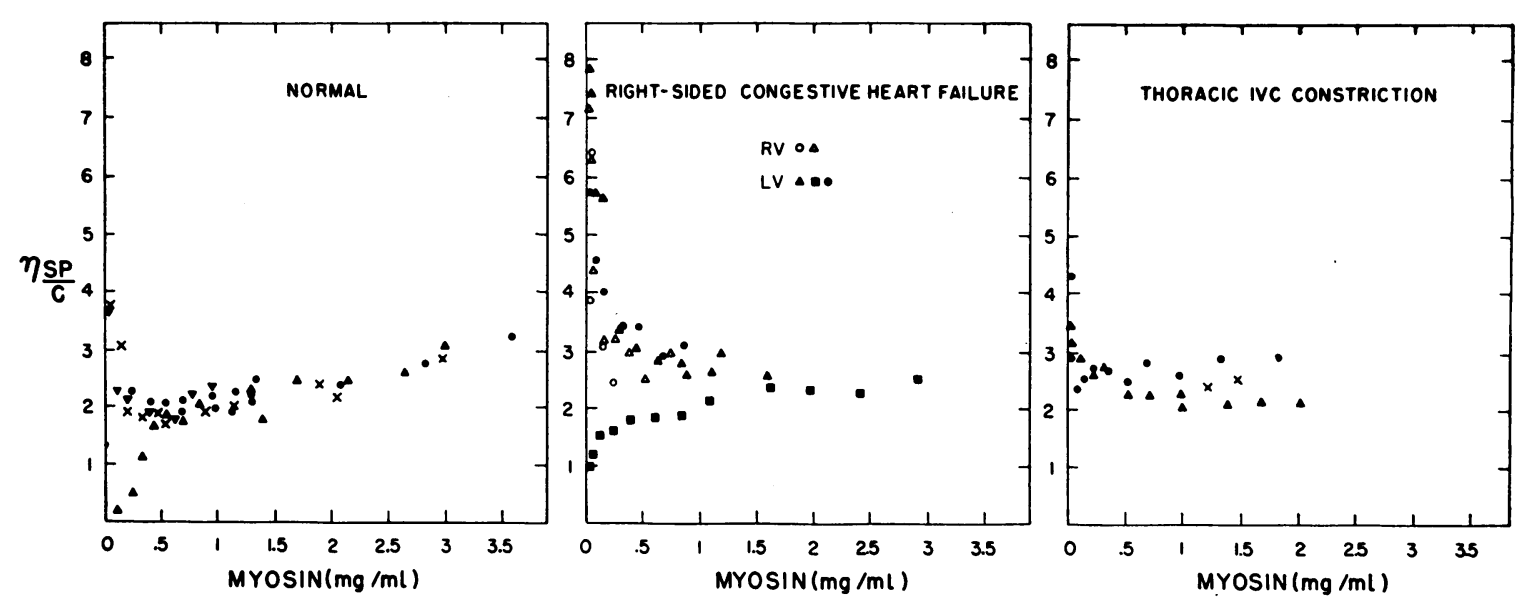

Fig. 4. SPECific viscosity/Concentration $\left(\eta_{\mathrm{sp}} / \mathrm{C}\right)$ of Myosin PLotTed against the protein Concentration. 
ventricle of a dog with right heart failure gave similar response to one myosin preparation from a normal heart in that $\eta_{\mathrm{sp}} / \mathrm{C}$ decreased progressively at very low myosin concentrations.

\section{DISCUSSION}

The present physicochemical measurements of cardiac myosin have yielded results very similar to those reported for skeletal muscle myosin $(1-7)$. There is good agreement $(3-7)$ that the $\mathrm{S}_{20, \mathrm{w}}$ for skeletal muscle myosin is in the range of 6.15 to $6.40 \times 10^{-13}$ seconds. Laki and Carroll (4) obtained a value of $1.0 \times 10^{-7} \mathrm{~cm}^{2}$ per second for the diffusion coefficient of skeletal myosin. If the peculiar viscosity behavior at concentrations below $0.4 \mathrm{mg}$ per $\mathrm{ml}$ is neglected, the present measurements of the intrinsic viscosity of cardiac myosin from normal hearts show a value of 1.8 which is similar to that reported by others $(1,2$, 7) for skeletal muscle myosin. Calculations of the molecular weight of cardiac myosin from normal heart muscle, from the present $S_{20, w}$ of $6.17 \times 10^{-13}$ seconds and the diffusion coefficient of $1.1 \times 10^{-7}$ $\mathrm{cm}^{2}$ per second, give a value of 501,000. However, the scatter of sedimentation and diffusion constants is sufficient to include values from 450,000 to 550,000 for the molecular weight.

Also, the findings in this study are in excellent agreement with the results of Gergely and Kohler (9) from studies of normal cardiac myosin. They obtained a value of 500,000 for the molecular weight from light scattering measurements. The present data and those of Gergely and Kohler appear to be at variance with the finding of Olson (8) of a value of 223,000 for normal cardiac myosin. However, the results from all three laboratories would be reconcilable if Olson's myosin preparations consisted of monomers, whereas the cardiac myosin prepared by Gergely and Kohler and the present preparations consisted mostly of myosin in the form of dimers.

The close similarity of the magnitude of the parameters from the present data on cardiac myosin to those of Holtzer and Lowey (7) and others (2-6) for skeletal myosin suggests that the shape of the cardiac myosin molecule is very similar, if not identical, to that for skeletal myosin. From sedimentation, viscosity and light scattering measurements, Holtzer and Lowey (7) reported a molecular weight of 493,000 for skeletal muscle myosin. They suggested that myosin is a rod $1,620 \AA$ long and $26 \AA$ thick. If myosin preparations which yield values of approximately 500,000 for the molecular weight consist mostly of dimers, it appears that the two monomers of myosin are arranged end-to-end to form a dimer. In this event, the molecular dimensions described by Holtzer and Lowey (7) would apply to the dimer.

Another similarity between the present cardiac myosin preparation and skeletal muscle myosin is the occurrence of polydispersity. The diffusion data in this study provide evidence for a polydisperse system from analysis of the normalized fringe distances at different levels in the diffusing boundary. In the ultracentrifuge patterns, the occasional presence of a small sedimentation component which moved faster than the principal sedimenting boundary is probably a reflection of polymerized myosin. Aggregation of the basic myosin monomer, with the resultant appearance of a fast-moving component during ultracentrifugation, has been observed for skeletal muscle myosin $(7,17)$.

The present viscosity measurements of cardiac myosin showed a peculiar finding in very dilute solutions (below $0.5 \mathrm{mg}$ per $\mathrm{ml}$ ). The $\eta_{\mathrm{sp}} / \mathrm{C}$ increased markedly in some preparations and decreased in others. The phenomenon occurred with myosin from both normal and failing hearts and with cardiac myosin from dogs with thoracic caval constriction. Similar changes in the viscosity of cardiac myosin at low concentrations have been reported previously by Olson (8). In view of the the irreproducibility of the viscosity measurements among different myosin preparations from the same sources of material (normal or failing ventricle), the possibility must be considered that viscosity measurements at very low concentrations do not represent the true viscosity of the solution. It does not seem likely that the viscosity changes at low concentrations were the result of the temperature $\left(22.5^{\circ} \mathrm{C}\right)$ at which viscosity was measured, since Olson (8) observed the same peculiar viscosity at $1^{\circ} \mathrm{C}$. Also, Holtzer and Lowey (7) concluded that the slight difference in intrinsic viscosity of myosin measured at $1^{\circ}$ and at $26^{\circ} \mathrm{C}$ was probably not significant.

The results of this study show no difference between cardiac myosin from normal dog hearts and from either the right or left ventricle of dogs 
with right-sided congestive failure secondary to tricuspid insufficiency and pulmonic stenosis. Also, left ventricular myosin from the one dog with naturally occurring right and left ventricular failure appeared normal. These findings are in contrast to the results of Olson (8) who reported that an abnormal cardiac myosin was extracted from the combined right and left ventricles of dogs with tricuspid insufficiency and pulmonic stenosis. Olson and Piatnek (18) reported that their dogs with tricuspid insufficiency and pulmonic stenosis were in left ventricular failure.

In the present study, cardiac myosin was obtained from separate right and left ventricles of the animals with cardiac failure. This procedure was adopted so that myosin from the specific failing chamber (right or left ventricle) could be compared with normal material. There was no evidence for left ventricular failure in the present dogs with tricuspid insufficiency and pulmonic stenosis, and an earlier more extensive study (13) also revealed pure right-sided cardiac failure in dogs with tricuspid insufficiency and pulmonic stenosis.

It has been suggested by Benson (19) that actomyosin is partially fragmented into uncombined myosin and actin in dogs with experimental cardiac failure secondary to tricuspid insufficiency and pulmonic stenosis. However, recent extensive studies of cardiac actomyosin (10) have failed to confirm the findings of Benson. Sedimentation velocity and viscosity measurements of cardiac actomyosin from the right ventricle of dogs with chronic experimental congestive failure, produced by either tricuspid insufficiency and pulmonic stenosis or by severe pulmonic stenosis alone, showed no evidence for altered actomyosin in 7 of 11 dogs. In the other four animals, a slow sedimenting component was present in the sedimentation diagrams but this appeared to be a preparation or extraction artifact. The present observations and those reported previously on actomyosin (10) offer no support for the view that altered contractile proteins constitute the biochemical defect in the failing heart.

SUMMARY AND CONCLUSIONS

The molecular weight of cardiac myosin was determined from sedimentation and free diffusion data; a value of approximately 500,000 was obtained for normal cardiac myosin. Measurements of the intrinsic viscosity of cardiac myosin from normal hearts showed a value of 1.8. Sedimentation velocity, viscosity and diffusion measurements of myosin showed no differences between myosin prepared from normal hearts and myosin obtained from failing ventricular muscle. Also, the present physicochemical constants for cardiac myosin are in good agreement with data described by others for skeletal muscle myosin.

\section{ACKNOWLEDGMENT}

We are grateful to Dr. Samuel Greenhouse and Mrs. Norma French for statistical analysis of the data.

\section{REFERENCES}

1. Szent-Gyorgyi, A. The Chemistry of Muscular Contraction, 2nd ed. New York, Academic Press, 1951.

2. Portzehl, H., Schramm, G., and Weber, H. H. Aktomyosin und seine Komponenten. Z. Naturforsch. 1950, 5b, 61 .

3. Parrish, R. G., and Mommaerts, W. F. H. M. Studies on myosin. II. Some molecular-kinetic data. J. biol. Chem. 1954, 209, 901.

4. Laki, K., and Carroll, W. R. Size of the myosin molecule. Nature (Lond.) 1955, 175, 389.

5. Von Hippel, P. H., Schachman, H. K., Appel, P., and Morales, M. F. On the molecular weight of myosin. Biochim. biophys. Acta 1958, 28, 504.

6. Mommaerts, W. F. H. M., and Aldrich, B. B. Determination of the molecular weight of myosin. Interference-optical measurements during the approach to ultracentrifugal sedimentation and diffusion equilibrium. Biochim. biophys. Acta 1958, 28, 627.

7. Holtzer, A., and Lowey, S. The molecular weight, size and shape of the myosin molecule. J. Amer. chem. Soc. 1959, 81, 1370.

8. Olson, R. E. Myocardial metabolism in congestive heart failure. J. chron. Dis. 1959, 9, 442.

9. Gergely, J., and Kohler, H. Molecular parameters of cardiac myosin. Fed. Proc. 1957, 16, 185.

10. Davis, J. O., Trapasso, M., and Yankopoulos, N. A. Studies of actomyosin from cardiac muscle of dogs with experimental congestive heart failure. Circulat. Res. 1959, 7, 957.

11. Davis, J. O., and Howell, D. S. Mechanisms of fluid and electrolyte retention in experimental preparations in dogs. II. With thoracic inferior vena cava constriction. Circulat. Res. 1953, 1, 171. 
12. Davis, J. O., Hyatt, R. E., and Howell, D. S. Rightsided congestive heart failure in dogs produced by controlled progressive constriction of the pulmonary artery. Circulat. Res. 1955, 3, 252.

13. Yankopoulos, N. A., Davis, J. O., McFarland, J. A., and Holman, J. Physiologic changes during chronic congestive heart failure in dogs with tricuspid insufficiency and pulmonic stenosis. Circulat. Res. 1959, 7, 950.

14. Gergely, J. Personal communication.

15. Lundgren, H. P., and Ward, W. H. Amino acids and proteins. Springfield, Ill., Charles C Thomas, 1951, chap. VI.
16. Longsworth, L. G. Diffusion measurements, at $1^{\circ}$, of aqueous solutions of amino acids, peptides and sugars. J. Amer. chem. Soc. 1952, 74, 4155.

17. Blum, J. J., and Morales, M. F. The interaction of myosin with adenosine triphosphate. Arch. Biochem. 1953, 43, 208.

18. Olson, R. E., and Piatnek, D. A. Conservation of energy in cardiac muscle. Ann. N. Y. Acad. Sci. 1959, 72, 466.

19. Benson, E. S. Composition and state of protein in heart muscle of normal dogs and dogs with experimental myocardial failure. Circulat. Res. 1955, 3,221 . 